\title{
Mitigation for Hawser's Short Fatigue Life on The Study of The Fatigue Life Prediction of Hawser in Single Point Mooring (SPM) at Tuban Fuel Terminal
}

\author{
Ahmad Syafiul Mujahid, ${ }^{\mathrm{a}, *}$ \\ a) Research Engineer, Laboratory for Hydrodynamics Technology - Agency for Assessment and Application Technology, Indonesia \\ *Corresponding author: ahmadsmujahid@gmail.com
}

\section{Paper History}

Received: 23-August-2019

Received in revised form: 20-October-2019

Accepted: 30-November-2019

\begin{abstract}
One of the vital components of SPM System is Mooring Hawser. Mooring Hawser is mooring lines that used to anchor the tanker ship that is berthed at Single Point Mooring (SPM) fuel terminal to loading or offloading the fuel oil. The incident of broken hawser unexpectedly due to short fatigue life that occurs on hawser when tanker ship that is anchored at SPM 150.000 DWT at Tuban Seas, East Java, Indonesia is the basis of this study for mitigation and replace of new hawser. This study calculates fatigue life of the hawser by using numerical simulation approach and Palmgren-Miner Methods. The hawser variation that conducted is only at the size of the outside diameter, namely: $0.144 \mathrm{~m}, 0.152 \mathrm{~m}$, and $0.160 \mathrm{~m}$. The material properties of the hawser in this study are Nylon Polyamide PA66. Numerical simulation consist of two steps: Hydrodynamics diffraction numerical simulation is used to obtain response (RAO) of tanker ship and SPM, and hydrodynamics time response numerical simulation is used to obtain effective hawser tension time history in 3600 second time simulation. By using the S-N Curve of Nylon Polyamide PA66 is obtained from Jernej Klemenc, Andrej Wagner, and Matija Fadjiga (2011) as the basis to calculate fatigue life prediction of three variations in the outside diameter of the hawser with Palmgren-Miner methods. The calculation result of new hawser fatigue life $=57.40536$ Months or 4.718249 Years of Effective Berthing Time. The new hawser use outside diameter variation $=0.152 \mathrm{~m}$ to replace the previous hawser.
\end{abstract}

KEY WORDS: Mitigation, Fatigue Life, Hawser, Numerical Simulation, Palmgren-Miner.

\section{NOMENCLATURE}

A Cross-section area $\left[\mathrm{m}^{2}\right]$

B Damping (frequency dependent)

C Hydrostatic stiffness

D Cumulative damage ratio

e Damping coefficient of the line [s]

EA Axial stiffness of line, as specified on the line type form

F Wave force (incident and diffracting forces)

$\mathrm{H} \quad$ Response function of object motion

$\mathrm{L} \quad$ Instantaneous length of segment [m]

Lo Un-stretched length of segment [m]

$\mathrm{M}_{\mathrm{s}} \quad$ Structure mass

$\mathrm{M}_{\mathrm{a}} \quad$ Added mass (frequency dependent)

$\mathrm{n}_{\mathrm{i}} \quad$ Number of occurrence

$\mathrm{N}_{\mathrm{fi}} \quad$ Cycle to failure (S-N Curve)

$\mathrm{S}_{\theta \theta}(\omega)$ Spectra density of object $\theta$,

$\mathrm{S}_{\zeta \zeta}(\omega) \quad$ Spectra density of wave elevation $\zeta$.

$\mathrm{Te} \quad$ Effective tension $[\mathrm{kN}]$

$\mathrm{T}_{\text {mean }} \quad$ Mean tension $[\mathrm{kN}]$

$\mathrm{T}_{\max } \quad$ Maximum tension $[\mathrm{kN}]$

$\mathrm{T}_{\mathrm{wfmax}} \quad$ Maximum wave frequency tension $[\mathrm{kN}]$

$\mathrm{T}_{\mathrm{wfsig}} \quad$ Significant wave frequency tension $[\mathrm{kN}]$

$\mathrm{T}_{\text {lfmax }} \quad$ Maximum low-frequency tension $[\mathrm{kN}]$

$\mathrm{T}_{\text {lfsig }} \quad$ Significant low-frequency tension [kN]

$\mathrm{U}_{\mathrm{a}}(\omega)$ Amplitude of frequency $\omega$ of object $\theta$,

$\mathrm{X} \quad$ Object motion response

$\zeta_{\mathrm{a}}(\omega) \quad$ Amplitude of frequency $\omega$ of wave elevation

dLdt Rate of increase of length $[\mathrm{m} / \mathrm{s}]$

$\Phi \quad$ Diameter [m]

$\sigma \quad$ Hawser Stress [kPa] 


\subsection{INTRODUCTION}

Mooring hawser or hawser is mooring lines that used to anchor the tanker ship that are berthed (tandem) at Single Point Mooring (SPM) fuel terminal to loading or offloading the fuel oil as shown at Figure 1 below. In the previous research, author had discussed the study about broken hawser that occurs on tanker ship that is anchored at SPM 150.000 DWT at Tuban Seas, East Java, Indonesia. The broken hawser incident to be particular concern because hawser was broken suddenly (unexpectedly) and the hawser fatigue life based on actual condition is too short than hawser fatigue life that was scheduled previously. All this time, the method that used to replace the hawser only use non-scientific assumption, so that after the research has been conducted by calculated fatigue life prediction using Palmgren-Miner methods it is known that the previous hawser with a outside diameter of $0.144 \mathrm{~m}$ used is only capable of operating in a relatively too short period of time, that is $3197: 22: 48$ hours or equal to 4.44 months (calculated when the tanker ship berthing to SPM terminal). The calculation result value of hawser fatigue life is very close with real data value of hawser fatigue life that is: 3003:28:00 hours equal to 4.17 months, so that the accuracy ratio between actual lifetime versus lifetime based on prediction is $93.94 \%$ [2]. This problem will be discussed in this paper to obtain a quick mitigation solution to replace the previous hawser and to obtain a new hawser with a relatively long service life so that it can reduce the risk incident as before.
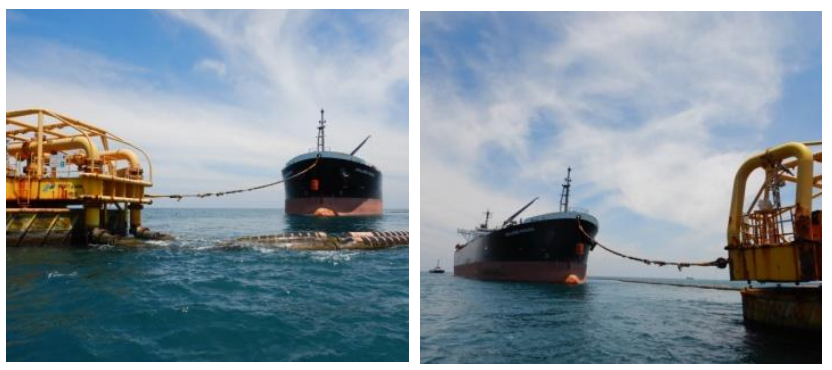

Figure 1: Tanker ship moored at SPM 150.000 DWT by using the hawser.

Some researchers have conducted studies on fatigue and lifetime prediction, that are: Klemenc (2011) study about fatigue characteristic of Nylon Polyaminde PA66 material with various configuration by using the fatigue test method, from this study then obtained S-N curve of nylon polyamide PA66 material with several variations, this $\mathrm{S}-\mathrm{N}$ curve was used in this author's research to calculate the hawser lifetime. Mujahid (2017) studied the fatigue life prediction of Landing Craft Tank Vessel's Rudder Stock that affected by extreme wave loads in Kalimantan Seas based on numerical simulation and Palmgren - Miner Formula to obtained rudder stock lifetime. $\mathrm{Xu}$ (2018) had discussed the fatigue strength of hull structure strength in hatch corner of the ultra large container ship's caused by torsion and bending stress. He used the spectral analysis method and used the influence of different environmental, speeds and loading conditions, and result is used to optimization new ship design and the safety assessment of the structure. Szala (2011) had calculated the method of fatigue life of structural elements based on the relations between fatigue life diagrams that determined in constant-amplitude conditions by Wöhler diagrams and those obtained under programmed or random loads. This method was experimentally verified by using results of fatigue tests on structural elements made of D16CzATW aluminum alloy.

The mitigation that conducted in this research is only by replace the hawser diameter size based on fatigue life prediction calculation by using Palmgren-Miner Methods, but the material type and product that is used is similar to the previous hawser, this is conducted to obtain a new hawser quickly with the right diameter and easily available on the market, so that the hawser replacement can be conducted immediately which has implications for smoothness the process of fuel oil loading and offloading of tanker ship on SPM. The study of mitigation for hawser's short fatigue life on the study of the fatigue life prediction of hawser in Single Point Mooring (SPM) at Tuban Fuel Terminals is presented on the flow diagram that presented in Figure 2.

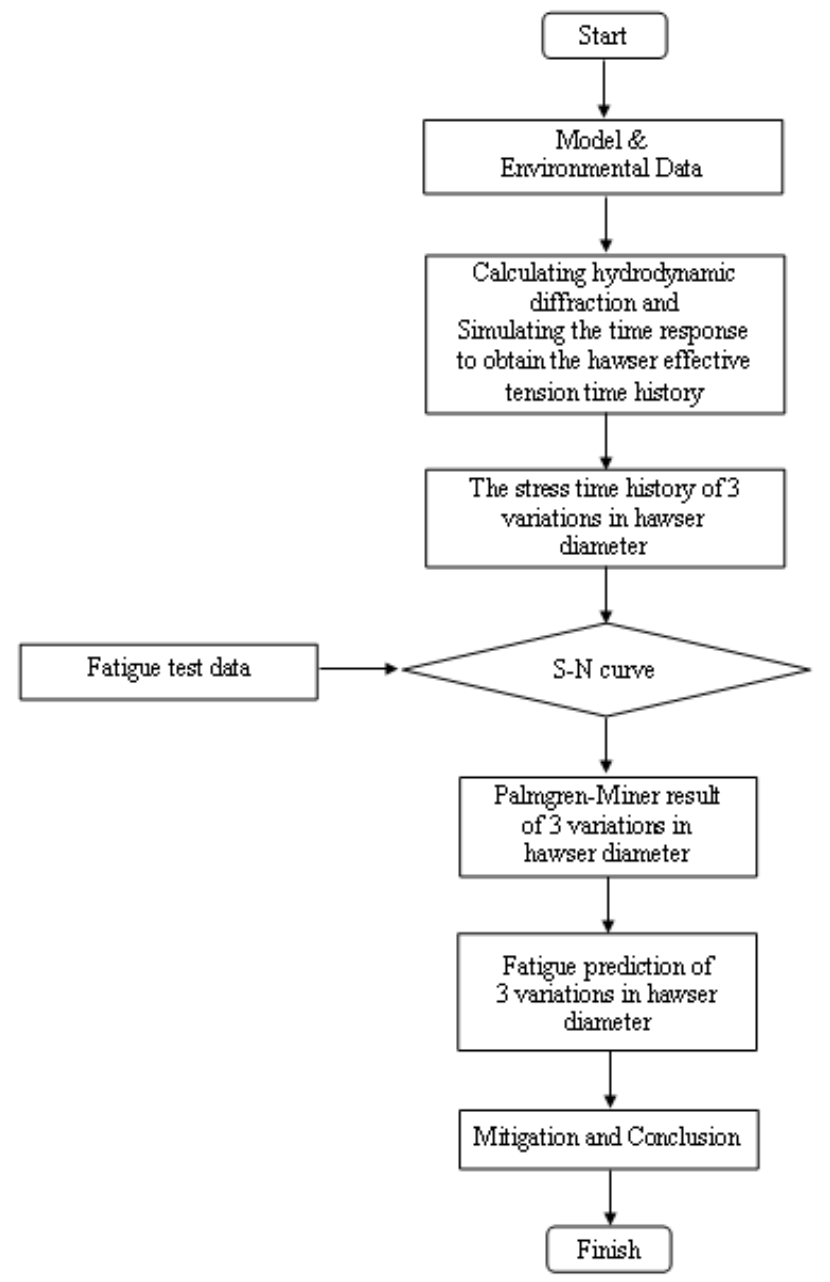

Figure 2: Flow diagram of the study

This paper mainly presents a study to mitigate the shortfatigue life of the previous hawser incident by combining 
numerical simulation to simulate cyclic load of environmental load and obtain the stress time history of effective tension of the hawser; and using the Palmgren-Minner Formula to obtain the fatigue life of the hawser in 3 variations of hawser diameter. All step of the study is shown in Figure 2 above and will be discussed more detail in the next chapter of this paper.

\subsection{THEORY}

\subsection{Model and Environmental Data}

To ensure that the simulation is representing the real environment condition then the simulation's input data is must be accurate. The environmental data in Tuban Seas are shown in Table 1. The data that used is 100 years period as a purpose to simulate environmental load in the extreme weather condition so that is obtained the big cyclic loads. The direction relative to tanker ship of wave, wind, and sea current are used 180 degree direction or head sea that is shown in Figure 3.

Table 1: Environmental Data

\begin{tabular}{|c|c|c|}
\hline \multicolumn{3}{|c|}{ Remarks } \\
\hline \multicolumn{3}{|c|}{ (100 years Period) } \\
\hline Item & Value & Unit \\
\hline \multicolumn{3}{|l|}{ Wind } \\
\hline Wind Velocity & 21.2 & $\mathrm{~m} / \mathrm{s}$ \\
\hline Density & 0.00128 & $\mathrm{te} / \mathrm{m}^{\wedge} 3$ \\
\hline Kinematic Viscosity & $1.50 \mathrm{E}-05$ & $\mathrm{~m}^{\wedge} 2 / \mathrm{s}$ \\
\hline Direction & 180 & degree \\
\hline \multicolumn{3}{|l|}{ Wave } \\
\hline Significant Wave Height & 4.6 & meter \\
\hline Significant Wave Period & 8.7 & $\mathrm{~s}$ \\
\hline Direction & 180 & degree \\
\hline Wave type & \multicolumn{2}{|c|}{ JONSWAP } \\
\hline \multicolumn{3}{|l|}{ Sea-Current } \\
\hline Velocity & 1.2 & $\mathrm{~m} / \mathrm{s}$ \\
\hline Direction & 180 & degree \\
\hline Sea Water Density & 1025 & $\mathrm{~kg} / \mathrm{m}^{3}$ \\
\hline Sea Depth & 30 & $\mathrm{~m}$ \\
\hline
\end{tabular}

Wave, wind, and sea current direction in numerical simulation using direction 180 degree as shown in Figure 3 as configuration to obtain the long $\mathrm{x}$-axis translation (surge) distance between tanker ship and SPM, so this configuration and by using the 100 years period data will be obtained the bigger effective tension of the hawser in time history from numerical simulation result.

In this simulation, tanker data that used are tanker ship with the bigger displacement that usually operated there, where main dimension of tanker ship that used in this case is shown in Table 2, whereas the drawing of tanker ship in two dimension is shown in Figure 4, and tanker ship model in three dimension and its mesh in numerical simulation is shown in Figure 5.

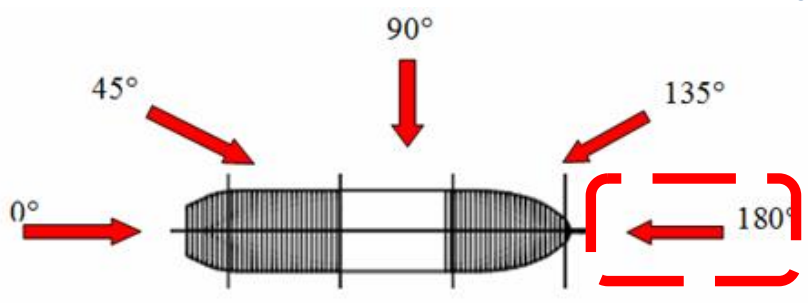

Figure 3: Wave, wind, and sea current direction in the simulation

The tanker ship that allowed to berth at SPM 150.000 DWT in Tuban Seas is tanker ship which has a displacement that not bigger than SPM loading capacity.
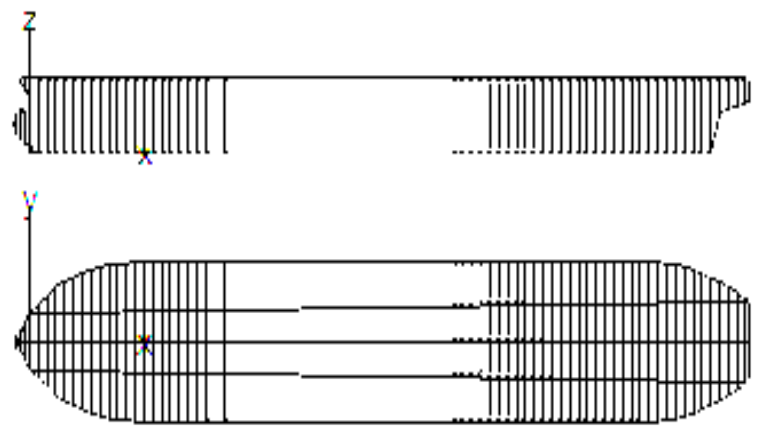

Figure 4: Tanker ship drawing in two dimension . (Top) side view. (Bottom) top view.

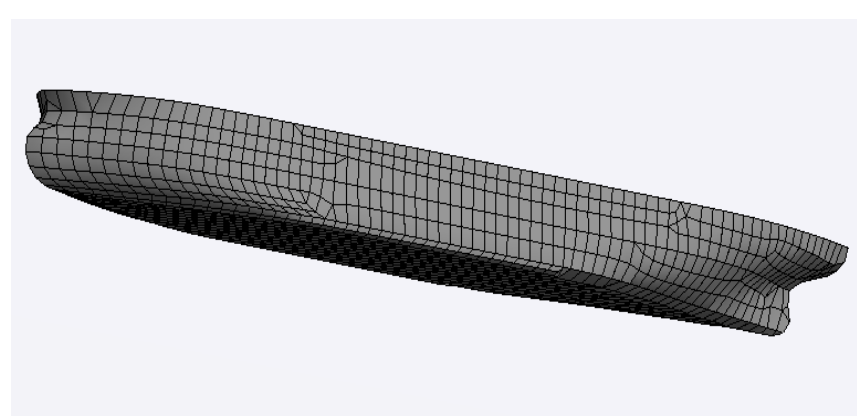

Figure 5: 3D modeling of tanker ship and its mesh.

Table 2: Tanker ship data

\begin{tabular}{|c|c|c|c|}
\hline Item & Symbol & Value & Units \\
\hline Displacement & $\Delta$ & 100856 & Tonne \\
\hline Volume & $\nabla$ & 98396 & $\mathrm{~m}^{\wedge} 3$ \\
\hline Length waterline & Lwl & 235.601 & $\mathrm{M}$ \\
\hline Beam & $\mathrm{B}$ & 42 & $\mathrm{M}$ \\
\hline Draft & $\mathrm{D}$ & 13 & $\mathrm{M}$ \\
\hline Block Coefficient & $\mathrm{Cb}$ & 0.765 & - \\
\hline Radius of Gyration - x & Kxx & 14.28 & $\mathrm{M}$ \\
\hline Radius of Gyration - y & Kyy & 58.9 & $\mathrm{~m}$ \\
\hline Radius of Gyration - z & Kzz & 61.26 & $\mathrm{~m}$ \\
\hline
\end{tabular}


Single Point Mooring (SPM) is a floating structure located offshore that serves as a mooring place and interconnection for tanker ship loading oil and offloading. SPM 150.000 DWT is one of Tuban Fuel Terminal's Facility as loading-unloading and mooring device for Tankers. SPM 150.000 DWT data is shown in Table 3 and SPM 150.000 DWT drawing is shown in Figure 6 below. The SPM 150.000 DWT data and drawing are used to modeling SPM object well in numerical simulation.

Table 3: SPM 150.000 DWT data

\begin{tabular}{|l|l|l|}
\hline \multicolumn{1}{|c|}{ Item } & \multicolumn{1}{c|}{ Value } & \multicolumn{1}{c|}{ Units } \\
\hline Load Capacity & 150.000 & DWT \\
\hline Outside Diameter & 11 & $\mathrm{~m}$ \\
\hline Inside Diameter & 3.7 & $\mathrm{~m}$ \\
\hline Skirt Diameter & 15 & $\mathrm{~m}$ \\
\hline Buoy Height & 4.5 & $\mathrm{~m}$ \\
\hline Chain Stoppers & 6 & Units \\
\hline Anchor Chain Diameter & 2.75 & Inch \\
\hline SPM Weight & 150 & Ton \\
\hline Turntable Weight & 50 & Ton \\
\hline Buoy Weight & 100 & Ton \\
\hline
\end{tabular}

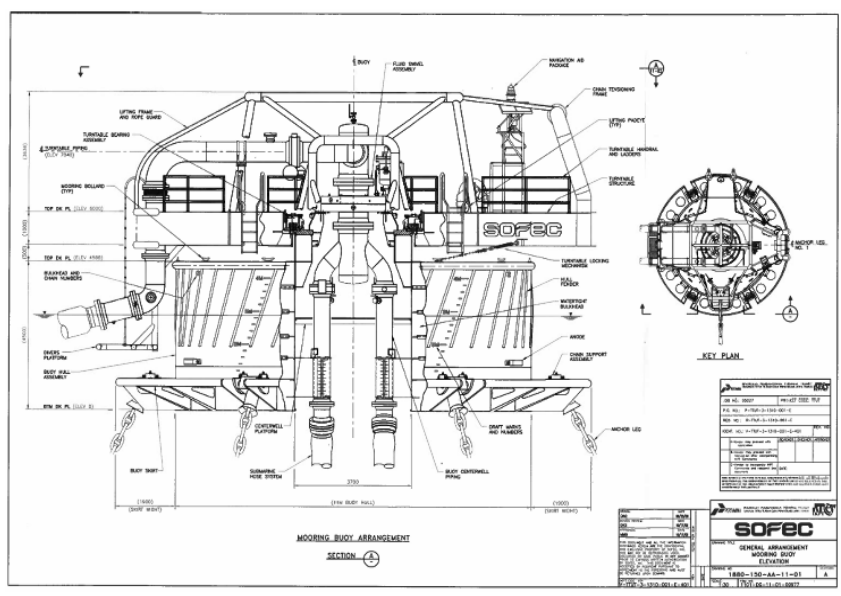

Figure 6: SPM 150.000 DWT drawing.

Mooring lines or spread mooring is a chain / mooring that connects anchors in seabed to fairlead in SPM, mooring lines are useful as anchors to keep SPM stay in the starting position. Whereas Hawser is a large-diameter rope that is usually made from polypropilene, rope, or made from nylon which is used to anchor tankers to SPM. In this study, the studied hawser object was made from polyamide nylon. Mooring lines and hawser datas are shown in Table 4, whereas hawser type that is used namely grommet type as shown in Figure 7. Table 4 shows the outside diameter size in 3 variation along with other specification values which follow like nominal circumference value and minimum breaking force value (new wet condition), whereas hawser length hawser is same each other.
Table 4: Mooring lines and hawser data

\begin{tabular}{|c|c|c|}
\hline Item & Value & Units \\
\hline \multicolumn{3}{|l|}{ Hawser $(\mathbf{H})$} \\
\hline Type Material & \multicolumn{2}{|c|}{ Polyamide (Nylon) } \\
\hline Color & \multicolumn{2}{|l|}{ Natural White } \\
\hline Outside Diameter & $144|152| 160$ & $\mathrm{~mm}$ \\
\hline Nominal Circumference & $452|478| 503$ & $\mathrm{~mm}$ \\
\hline Nominal Length & 55 & $\mathrm{~mm}$ \\
\hline Linear Density & 11.38 & $\mathrm{~kg} / \mathrm{m}$ \\
\hline \multirow{2}{*}{$\begin{array}{l}\text { Minimum Breaking Force } \\
\text { (New Wet Condition) }\end{array}$} & $\begin{array}{l}494 \\
551 \\
611\end{array}$ & tons \\
\hline & $\begin{array}{l}4391 \\
4905 \\
5435 \\
\end{array}$ & $\mathrm{kN}$ \\
\hline \multicolumn{3}{|l|}{ Mooring Lines (L) } \\
\hline Type & \multicolumn{2}{|c|}{$6 \times$ chain stud less } \\
\hline Chain diameter & 76.2 & $\mathrm{~mm}$ \\
\hline Min. Breaking Load (MBL) & 439.726 & ton \\
\hline
\end{tabular}

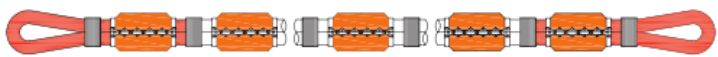

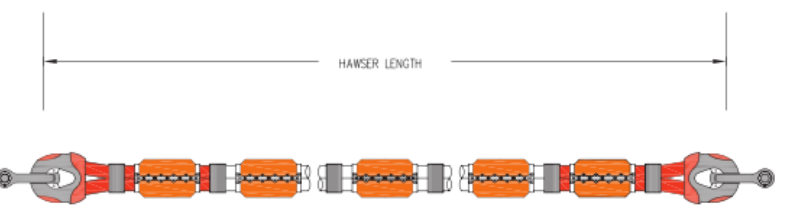

Figure 7: Grommet type hawser (Source: Lankhorst Ropes).

The numerical simulation configuration that carried out is refers to a case study in the fuel terminal at Tuban, where the configuration of tanker ship, SPM, hawser, and mooring lines is shown in Figure 8.

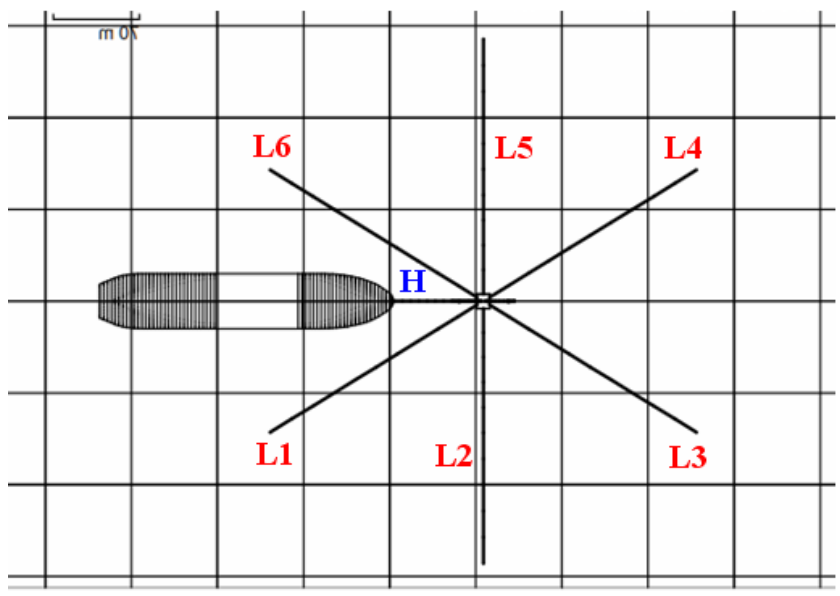

Figure 8: Configuration of mooring lines from top view. 


\subsection{Numerical Simulation}

Numerical simulation that conducted consists of 2 steps that are: hydrodynamics diffraction and hydrodynamics time response. Hydrodynamics diffraction simulation used to obtain response (RAO) of tanker ship and SPM, and hydrodynamics time response simulation used to obtain effective hawser tension time history. The numerical simulation is made by solving the response of structure in wave shown as below approximated using panel theory method [5].

$$
\left[-\omega^{2}\left(M_{s}+M_{a}(\omega)\right)-i \omega B(\omega)+C\right] X(\omega)=F(\omega)
$$

and

$$
H=\frac{u_{a}(\omega)}{\zeta_{a}(\omega)}=\sqrt{\frac{S_{\theta \theta}(\omega)}{S_{\zeta \zeta}(\omega)}}
$$

\subsection{Hawser Tension Force}

The motion between tanker ship and SPM due to envonmental load effect causes movement both of them, so that if the motion relative between tanker ship and SPM results distance that exceeds more than the haweser length it will cause the tension force to occur on the hawser. The maximum tension value of the hawser can be calculated using Formula (3) and (4), whereas the effective tension value of the hawser can be calculated using Formula (5) below:

$$
T_{l f \max }>T_{\text {wfmax }},
$$

then:

$$
\begin{aligned}
& T_{\text {max }}=T_{\text {mean }}+T_{\text {lfmax }}+T_{w f s i g} \\
& T_{\text {lfmax }}<T_{w f \text { max }},
\end{aligned}
$$

then:

$$
T_{\max }=T_{\text {mean }}+T_{w f \max }+T_{l f s i g}
$$

and

$$
T e=E A \cdot\left[\frac{(L-L o)}{L o}+\frac{\left(e \cdot \frac{d L}{d t}\right)}{L o}\right]
$$

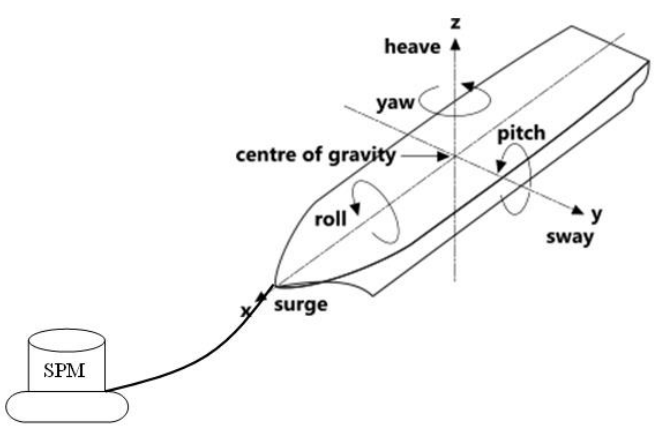

Figure 9: Six degree of freedom of tanker, SPM, and hawser.
As shown in Figure 3, the direction of wave, wind, and sea current in numerical simulation configuration is 180 degrees (headsea), the aim is to obtain the maximum surge value on the tanker to SPM so it obtained the maximum tension load on the hawser. Surge is a translational movement in the direction of the $\mathrm{x}$ axis that shows the forward or backward motion of a ship, surge is one of the movements in the six degree of freedom as the scheme that is shown in Figure 9 below. The simulation time used is 3600 seconds or 1 hour, assuming that the cycle of load is repeated after 1 hour.

\subsection{Hawser Stress}

As it is known that the fatigue life of the hawser's material is to be short due to the many occurrences of hawser tension that exceeds the threshold value limit that can be seen from the S-N curve material hawser namely Nylon Polyamide PA66. If the effective tension force value of the hawser is constant, the value of the stress hawser can be reduced by enlarging the cross-sectional area of the hawser as shown in Formula (6) bellowed, it is shows relation between hawser stresses versus cross-sectional area of hawser.

$$
\sigma=\frac{T e}{A}
$$

Outside diameter of hawser is varied in 3 variations as shown in Figure 10, namely: $0.144 \mathrm{~m}, 0.152 \mathrm{~m}$, and $0.160 \mathrm{~m}$. the outside diameter variation of the hawser that chosen is one or two levels larger than the outside diameter of previous hawser where the outside diameter size is selected based on the catalog of product availability (ready stock) so as to facilitate the mitigation process of replacing the new hawser.
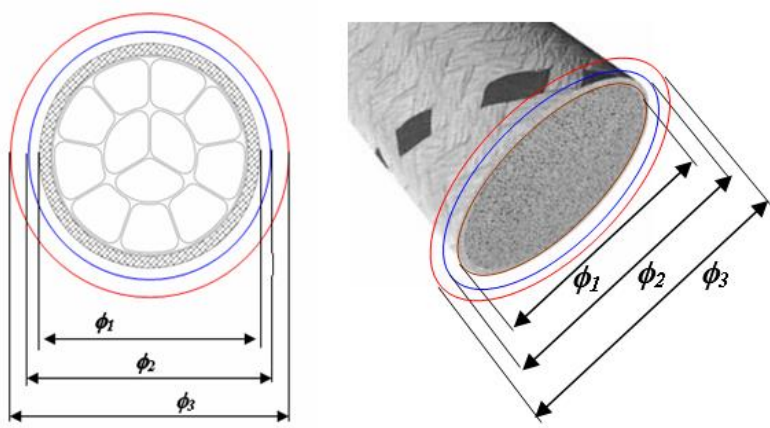

Figure 10: 3 variations of hawser outside diameter (Source: BRIDON)

\subsection{Fatigue Analysis Method}

Fatigue of a hawser material is defined as progressive damage that occurs to the hawser due to a cyclic load. If the large loads occur repeatedly (cyclic load) in a much quantities, they can cause material failure or fatigue of the hawser material. Fatigue life is a term that used to determine the number of load cycles that occur before failure. Fatigue strength is the maximum stress achieved in the stress cycle used to determine the fatigue life. Fatigue life depends on several factors such as cyclic frequency, load repetition, load factor, and other factors such as temperature and humidity. 
The hawser obtains a lot of repetitive / cyclic loads that cause a decrease in its strength. Fatigue analysis is important to predict fatigue life. The cyclic stress can cause physical damage to the hawser. That value can be calculated by using $\mathrm{S}-\mathrm{N}$ curve nylon polyamide PA66 which is the basic material of the hawser.

The cumulative Palmgren-Miner damage rule is a simple criterion for predicting the level of fatigue damage caused by repetitive loads, Palmgren-Miner Formula that used to calculate fatigue life is shown at Formula (7) below:

$$
D=\sum_{i=1}^{n} \frac{n_{i}}{N_{f i}}=1
$$

Where:

$$
\text { Fatigue Life }=\frac{1}{D}
$$

\subsection{RESULT AND DISCUSSION}

After conducted the numerical simulation of hydrodynamics diffraction then obtained characteristic values of tanker ship and SPM, one of them is RAO value (Response Amplitude Operator) as shown in the RAO graph in Figure 11.
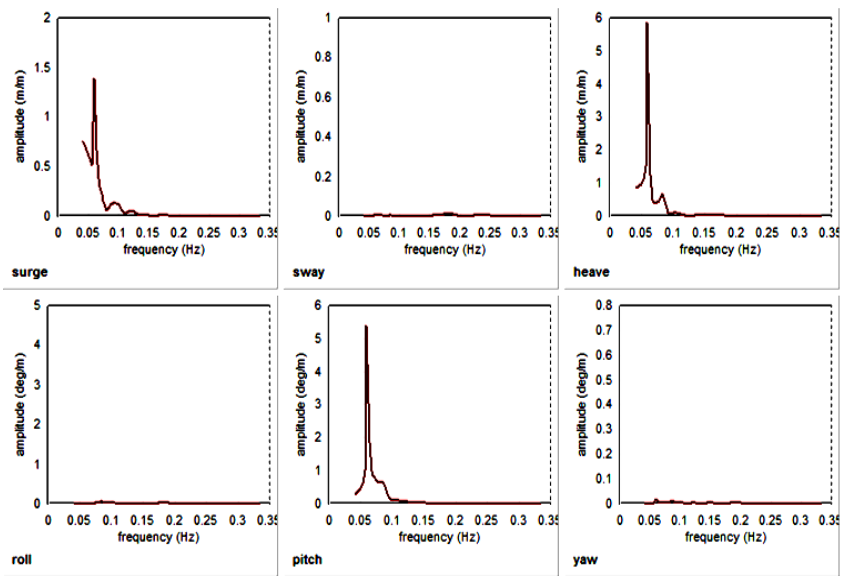

Figure 11: RAO graph of tanker ship.

Then the hydrodynamics diffraction simulation results are used as input to simulate tanker ship, SPM, and mooring configurations by using the numerical simulation of hydrodynamics time response as shown in Figure 12. The time of simulation that conducted is 3600 second, with the assumption that the environmental load such as: wave, wind, and sea current will repeat after one hour. The time of simulation will be used to calculate fatigue life of the hawser using Palmgren-Miner Formula.

From numerical simulation of hydrodynamics time response then obtained the effective tension time history values of the hawser that displayed in the form of a log-scale graph in Figure 13.

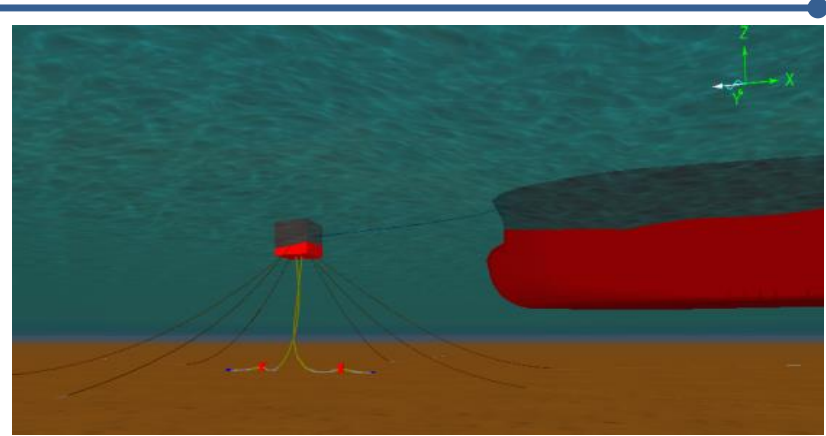

Figure 12: Underwater view of tanker ship, SPM, and mooring lines in numerical simulation.

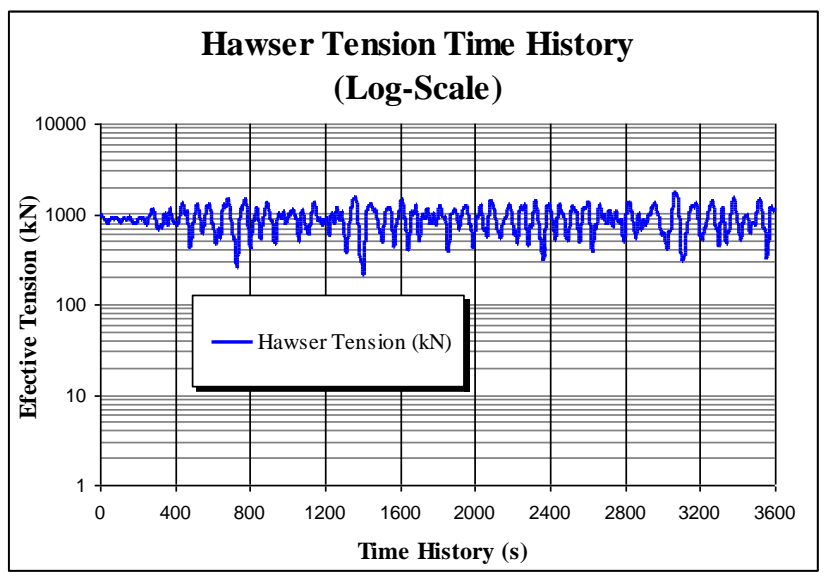

Figure 13: Graph of hawser effective tension force time history.

By divide the effective tension time history result to the cross section area of the hawser, then the Hawser's stress time history in three variations of the hawser's outside diameter is obtained as shown in Figure 14 below. From the Figure 14 shows that the stress time history value of the hawser becomes much lower as the size of the outside diameter of the hawser increases.

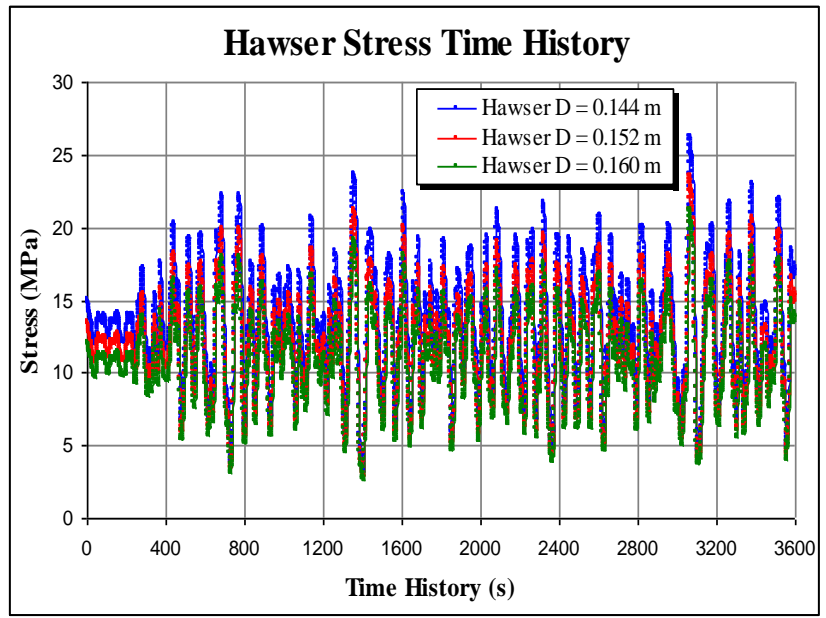

Figure 14: Graph of hawser stress time history in 3 diameter variations. 
S-N Curve and Threshold Value of $24.2 \mathrm{MPa}$ from nylon polyamide PA66 material were obtained from fatigue tests that are conducted by: Jernej Klemenc, Andrej Wagner, and Matija Fadjiga in the Scientific Journal entitled: "Modeling The SN Curve of Polyamide PA66 Using a Serial Hybrid Neural Network" from the Journal of Engineering Materials and Technology 2011. the S-N Curve of Nylon Polyamide PA66 material is shown in Figure 15.

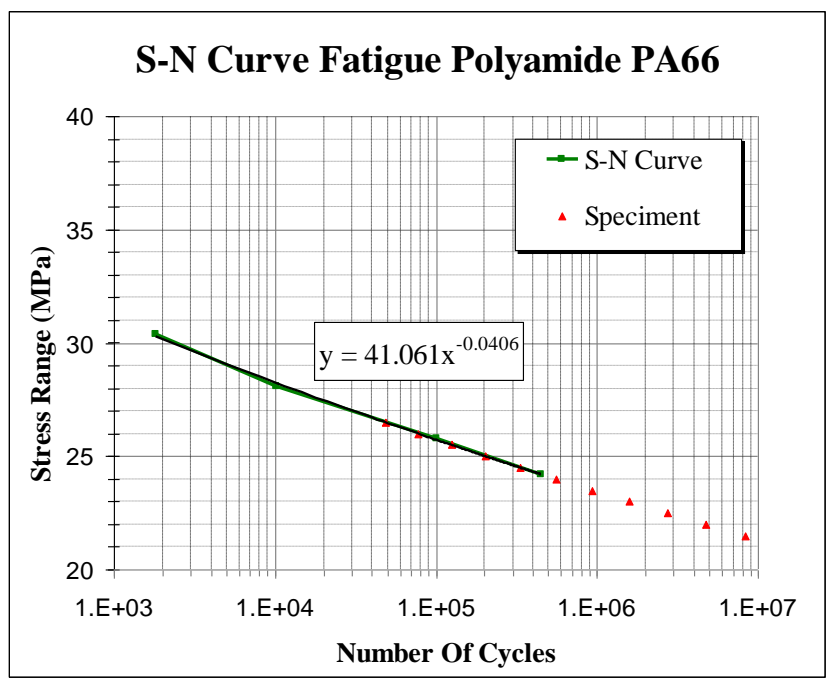

Figure 15: S-N curve of Nylon Polyamide PA66.

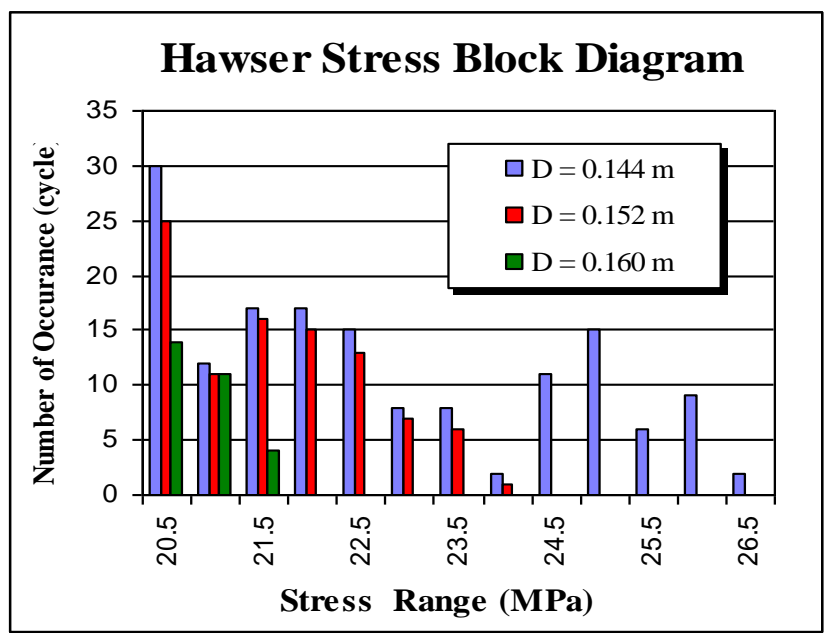

Figure 16: Hawser stress block diagram in 3 diameter variation.

By using S-N curve of Nylon Polyamide PA66, the hawser stress time history value for three variations of outside diameter can be grouped in hawser stress block diagrams based on the number of stress events with the minimum stress values are several levels below the material threshold value, the aim is hawser fatigue life of three diameter variations can be calculated. The grouping of stresses that occur on the hawser based on the number of occurent that often appear is displayed in the form of a hawser stress block diagram as shown in Figure 16.

Table 5: The hawser's fraction of life in diameter $0.144 \mathrm{~m}$

\begin{tabular}{|c|c|c|c|r|c|}
\hline No & $\begin{array}{c}\text { Stress Range } \\
\text { Mpa }\end{array}$ & $\begin{array}{c}\text { Stress CF } \\
\text { Mpa }\end{array}$ & $\begin{array}{c}\text { Number of } \\
\text { Occurences } \\
\left(\mathrm{n}_{i}\right)\end{array}$ & $\begin{array}{c}\text { Number of cycles } \\
\text { to fatigue } \\
\left(\mathrm{N}_{\boldsymbol{f}}\right)\end{array}$ & $\begin{array}{c}\text { Fraction of } \\
\text { Life } \\
\mathrm{n}_{i} / \mathrm{N}_{\boldsymbol{f}}\end{array}$ \\
\hline 1 & $>20-20.5$ & 20.5 & 30 & 26942320.49 & $1.11 \mathrm{E}-06$ \\
\hline 2 & $>20.5-21$ & 21 & 12 & 14882150.62 & $8.06 \mathrm{E}-07$ \\
\hline 3 & $>21-21.5$ & 21.5 & 17 & 8336084.719 & $2.04 \mathrm{E}-06$ \\
\hline 4 & $>21.5-22$ & 22 & 17 & 4732006.675 & $3.59 \mathrm{E}-06$ \\
\hline 5 & $>22-22.5$ & 22.5 & 15 & 2720540.951 & $5.51 \mathrm{E}-06$ \\
\hline 6 & $>22.5-23$ & 23 & 8 & 1583247.88 & $5.05 \mathrm{E}-06$ \\
\hline 7 & $>23-23.5$ & 23.5 & 8 & 932178.34 & $8.58 \mathrm{E}-0$. \\
\hline 8 & $>23.5-24$ & 24 & 2 & 554999.5325 & $3.60 \mathrm{E}-06$ \\
\hline 9 & $>24-24.5$ & 24.5 & 11 & 333987.3288 & $3.29 \mathrm{E}-05$ \\
\hline 10 & $>24.5-25$ & 25 & 15 & 203059.5785 & $7.39 \mathrm{E}-05$ \\
\hline 11 & $>25-25.5$ & 25.5 & 6 & 124679.9415 & $4.81 \mathrm{E}-05$ \\
\hline 12 & $>25.5-26$ & 26 & 9 & 77282.8454 & $1.16 \mathrm{E}-04$ \\
\hline 13 & $>26-26.5$ & 26.5 & 2 & 48342.18838 & $4.14 \mathrm{E}-05$ \\
\hline
\end{tabular}

$$
D=\sum_{i=1}^{n} \frac{n_{i}}{N_{f i}}=3.13 \mathrm{E}-04
$$

Total Fraction of Life $=1 / D$ then:

$$
\frac{1}{3.13 \times 10^{-4}}=3.19 \times 10^{3}
$$

The duration of simulation load repeats for 3600 seconds. The total fraction of life is $3.19 \times 10^{3}$. To obtain the value of hawser fatigue life, then the simulation time of repetitive loading for 3600 seconds must be multiplied by $3.19 \times 10^{3}$. The value of Hawser fatigue life with outside diameter of $0.144 \mathrm{~m}$ is: $3.20 \mathrm{x}$ $10^{3} \times 3600$ second $=\underline{\mathbf{3 1 9 7 . 3 8 5} \text { hours }}$ or $\mathbf{4 . 4 4 0 8 1 2}$ months.

As with the calculation above, the hawser fatigue life with outside diameter $0.152 \mathrm{~m}$ can be calculated using data in Table 6 , the hawser fatigue life with outside diameterf $0.160 \mathrm{~m}$ can be calculated using the data in Table 7.

Table 6: The hawser's fraction of life in diameter $0.152 \mathrm{~m}$

\begin{tabular}{|c|c|c|c|r|c|}
\hline No & $\begin{array}{c}\text { Stress Range } \\
\text { Mpa }\end{array}$ & $\begin{array}{c}\text { Stress CF } \\
\text { Mpa }\end{array}$ & $\begin{array}{c}\text { Number of } \\
\text { Occurences } \\
\left(\mathrm{n}_{i}\right)\end{array}$ & $\begin{array}{c}\text { Number of cycles } \\
\text { to fatigue } \\
\left(\mathrm{N}_{\boldsymbol{f}}\right)\end{array}$ & $\begin{array}{c}\text { Fraction of } \\
\text { Life } \\
\mathrm{n}_{\boldsymbol{i}} / \mathrm{N}_{\boldsymbol{t}}\end{array}$ \\
\hline 1 & $>20-20.5$ & 20.5 & 25 & 26942320.49 & $9.28 \mathrm{E}-07$ \\
\hline 2 & $>20.5-21$ & 21 & 11 & 14882150.62 & $7.39 \mathrm{E}-07$ \\
\hline 3 & $>21-21.5$ & 21.5 & 16 & 8336084.719 & $1.92 \mathrm{E}-06$ \\
\hline 4 & $>21.5-22$ & 22 & 15 & 4732006.675 & $3.17 \mathrm{E}-06$ \\
\hline 5 & $>22-22.5$ & 22.5 & 13 & 2720540.951 & $4.78 \mathrm{E}-06$ \\
\hline 6 & $>22.5-23$ & 23 & 7 & 1583247.88 & $4.42 \mathrm{E}-06$ \\
\hline 7 & $>23-23.5$ & 23.5 & 6 & 932178.34 & $6.44 \mathrm{E}-06$ \\
\hline 8 & $>23.5-24$ & 24 & 1 & 554999.5325 & $1.80 \mathrm{E}-06$ \\
\hline \multicolumn{7}{r}{} & & & $\mathbf{s u m}$ & $2.42 \mathrm{E}-05$ \\
\hline
\end{tabular}

$$
D=\sum_{i=1}^{n} \frac{n_{i}}{N_{f i}}=2.4 E-05
$$

Total Fraction of Life $=1 / D$ then:

$$
\frac{1}{2.42 \times 10^{-5}}=4.13 \times 10^{4}
$$

The value of Hawser fatigue life with outside diameter of $0.152 \mathrm{~m}$ is: $4.13 \times 10^{4} \times 3600$ second $=\underline{\mathbf{4 1 3 3 1 . 8 6} \text { hours }}$ or $\underline{57.40536}$ months. 
Table 7: The hawser's fraction of life in diameter $0.160 \mathrm{~m}$

\begin{tabular}{|c|c|c|c|c|c|}
\hline No & $\begin{array}{c}\text { Stress Range } \\
\mathrm{Mpa} \\
\end{array}$ & $\begin{array}{c}\text { Stress CF } \\
\mathrm{Mpa} \\
\end{array}$ & $\begin{array}{c}\text { Number of } \\
\text { Occurences } \\
\left(\mathrm{n}_{i}\right)\end{array}$ & $\begin{array}{c}\begin{array}{c}\text { Number of cycles } \\
\text { to fatigue } \\
\left(N_{f}\right)\end{array} \\
\end{array}$ & $\begin{array}{c}\text { Fraction of } \\
\text { Life } \\
\mathrm{n}_{i} / \mathrm{N}_{i} \\
\end{array}$ \\
\hline 1 & $>20-20.5$ & 20.5 & 14 & 26942320.49 & $5.20 \mathrm{E}-07$ \\
\hline 2 & $>20.5-21$ & 21 & 11 & 14882150.62 & $7.39 \mathrm{E}-07$ \\
\hline 3 & $>21-21.5$ & 21.5 & 4 & 8336084.719 & $4.80 \mathrm{E}-07$ \\
\hline & & & & sum & $1.74 \mathrm{E}-06$ \\
\hline
\end{tabular}

$$
D=\sum_{i=1}^{n} \frac{n_{i}}{N_{f i}}=1.74 \mathrm{E}-05
$$

Total Fraction of Life $=1 / D$ then:

$$
\frac{1}{1.74 \times 10^{-6}}=5.75 \times 10^{5}
$$

The value of Hawser fatigue life with outside diameter of $0.160 \mathrm{~m}$ is: $5.75 \times 10^{5} \times 3600$ second $=\underline{\mathbf{5 7 5 1 7 1 . 9} \text { hours }}$ or 798.8499 months.

Table 8: The hawser's fatigue life in 3 diameter variations

\begin{tabular}{|c|c|c|c|c|}
\hline \multirow{2}{*}{$\begin{array}{c}\text { iameter } \\
\mathrm{m}\end{array}$} & \multicolumn{3}{|c|}{ Fatigue life Prediction } & \multirow{2}{*}{$\begin{array}{c}\text { Fatigue Life } \\
\text { Status }\end{array}$} \\
\hline 0.144 & Hours & Months & Years & St97.385 \\
\hline 0.440812 & 0.364998 & Too Short \\
\hline 0.152 & 41331.86 & 57.40536 & 4.718249 & Sufficient \\
\hline 0.160 & 575171.9 & 798.8499 & 65.65889 & Too Long \\
\hline
\end{tabular}

Ftom three variation of outside diameter of the hawser, then the hawser that chosen to replace the previous hawser is hawser with outside diameter $0.152 \mathrm{~m}$ with the value of fatigue life prediction is 57.40536 Months or 4.718249 Years and this value is effective berthing time. If the average number of tanker ship that berthed at SPM 150.000 DWT are 97 ship per year, and the average of a tanker ship that berthed at SPM 150.000 DWT to loading / offloading is for 2 days, then the effectife berthing time in one year is $97 \times 2 / 30$ days $=6.467$ Months or 0.5389 Years and this value is bigger than effective berthing time value of previous hawser (Outside diameter $0.144 \mathrm{~m}$ ), so that the previous hawser have already broken before it can be inspected periodically every year (annual survey). Whereas the fatigue life prediction of effective berthing time of new hawser (outside diameter $0.152 \mathrm{~m}$ ) is bigger than the effectife berthing time in one year, so that the new hawser (outside diameter $0.152 \mathrm{~m}$ ) can be inspected by periodic checks every year (annual survey) so that it can reduce the risk of broken hawser unexpectedly.

\subsection{CONCLUSION}

From the results of this study are obtained several conclusions, namely:

1. Mitigation that be conducted to replace the previous hawser (outside diameter $0.144 \mathrm{~m}$ ) is by increasing the size of the outside diameter of the new hawser into $0.152 \mathrm{~m}$.

2. The new hawser with outside diameter $0.152 \mathrm{~m}$ has fatigue life prediction that calculated by using Palmgren-Miner Formula is 57.40536 Months or 4.718249 Years (effective berthing time)
3. By using the new hawser, it is possible to carry out annual surveys in every year, so it can reduce the risk of broken hawser unexpectedly.

\section{ACKNOWLEDGEMENTS}

The authors would like to convey a great appreciation to all peoples that have supported the implementation of this study.

\section{REFERENCE}

1. BRIDON. (2016). Single Point Mooring CALM Buoy and FPSO/FSO Offtake Hawser Assemblies.

2. Effendi, Ferdi Raditya. Chairul Dhany. Ahmad Syafiul M. (2018). Fatigue Life Prediction Method of Single Point Mooring (SPM)'s Mooring Hawser, Case Study: Tuban Fuel Terminal's SPM. World Maritime Technology Conference 2018.

3. Klemenc. Jernej, et al. (2011). Modelling the S-N Curve of Polyamide PA66 Using a Serial Hybrid Neural Network. Journal of Engineering Material and Technology.

4. Lankhorst Ropes. (2016). Rope for Single Point Mooring.

5. Mujahid Ahmad S. et al (2017). A Prediction Method of Fatigue Life at the Rudder Stock. Journal of Subsea and Offshore Science and Engineering (JSOSE) Vol. 9 Page 1-6.

6. Szala, Józef. Grzegorz Szala. (2010). A Fatigue Life Calculation Method for Structural Elements Made of D16CzATW Aluminum Alloy. POLISH MARITIME RESEARCH 3(66) 2010 Vol 17; pp. 8-17.

7. Xu, Min. (2018). Application of Spectral Analysis for Fatigue Assessment of Ultra Large Container Ships. World Maritime Technology Conference 2018. 